\title{
ARTES INDÍGENAS \\ NOTAS SOBRE A LÓGICA DOS CORPOS E DOS ARTEFATOS
}

Lucia Hussak Van Velthem

Como apreender, em sua diversidade, artes que paradoxalmente não compartilham da noção ocidental de arte? Este artigo objetiva explorar algumas das peculiaridades das artes indígenas e mais particularmente aquelas que são relativas ao corpo humano, como a pintura e outros adornos, articulados às noções nativas de corporalidade. [Abstract on page 243]

POVOS INDÍGENAS, ARTE E ESTÉTICA, CONCEPÇÕES NATIVAS, ORNAMENTAÇÃO CORPORAL WAYANA. 


\title{
ARTES INDÍGENAS: UMA INTRODUÇÃO'
}

\begin{abstract}
A história nacional, contemplada a partir da experiência e da memória das populações indígenas, apresenta uma sucessão de confrontos que eclodiram nos primeiros contatos, se perpetuaram ao longo dos séculos e permanecem sem término previsível. ${ }^{2}$
\end{abstract}

Há, contudo, crescente reconhecimento do direito dos índios à dife-

1 Este artigo apoia-se largamente em trabalhos anteriores, mencionados na bibliografia e não citados no texto.

2 Um exemplo: em setembro de 2009 os Guarani Kaiowa de Mato Grosso do Sul tiveram suas casas incendiadas a mando de fazendeiros da região. rença cultural, e enfatiza-se o fato de os índios explorarem de forma sustentável seus territórios, contribuindo efetivamente para a conservação ambiental na Amazônia e em outros biomas. O protagonismo indígena, efetivado mediante suas associações, amplia essas conquistas, convergindo para a valorização do papel dos povos indígenas na formação cultural do país.

As manifestações artísticas indígenas, que se expressam através de artefatos e grafismos, têm sido alvo, no Brasil, de algumas iniciativas positivas, em um contexto mais amplo de proteção dos patrimônios culturais indígenas, embora permaneçam incompreendidas e desvalorizadas pela maioria dos brasileiros. As ações afirmati-

vas articulam-se ao conceito de patrimônio cultural imaterial, cujo surgimento é parte de um longo processo que envolve diferentes países e instituições preocupados com a diversidade cultural. Paralelamente, órgãos nacionais, com a colaboração de universidades, museus, organizações não governamentais e as próprias associações indígenas, procuram aprimorar estratégias relativas à documentação de saberes tradicionais. Apesar de ocuparem lugar proeminente nos programas de salvaguarda, essas estratégias levantam uma série de questionamentos. Estudiosos do patrimônio imaterial indígena defendem a necessidade e a urgência dessa documentação, uma vez que ela garante às culturas indígenas um espaço no mapa mundial das culturas, muito embora o registro, em si, não assegure nem a sobrevivência, nem a continuidade da prática cultural (GALLOIS 2006:77). É preciso reconhecer, entretanto, que os registros, os inventários e também a documentação de coleções etnográficas contribuem para o fortalecimento das comunidades indígenas (Figura 1).

O desconhecimento acerca das produções artísticas indígenas impede que se considerem sua contemporaneidade e, evidentemente, sua antiguidade, esta evidenciada por estudos arqueológicos, uma vez que as primeiras obras de arte de nosso país tiveram origem nas sociedades indígenas, há milhares de anos. Na realidade a dificuldade talvez resida no fato de que, nas cidades, as pessoas experimentam certa estranheza ao se deparar com expressões artísticas formuladas segundo critérios não hegemônicos. Nesse confronto devem discernir a origem da valoração estética de um artefato que se organiza através de materiais, palavras, usos, hábitos, mobilidades e contextos completamente diversos dos habituais. Assim, quando levadas a admirar um objeto indígena, as pessoas se veem diante da possibilidade de experimentar uma situação que constitui o reverso de seu próprio olhar que habitualmente busca interpretar uma obra, já qualificada e definida como artística em sua própria sociedade (NAHOUM-GRAPPE, 2004). Em ou- 

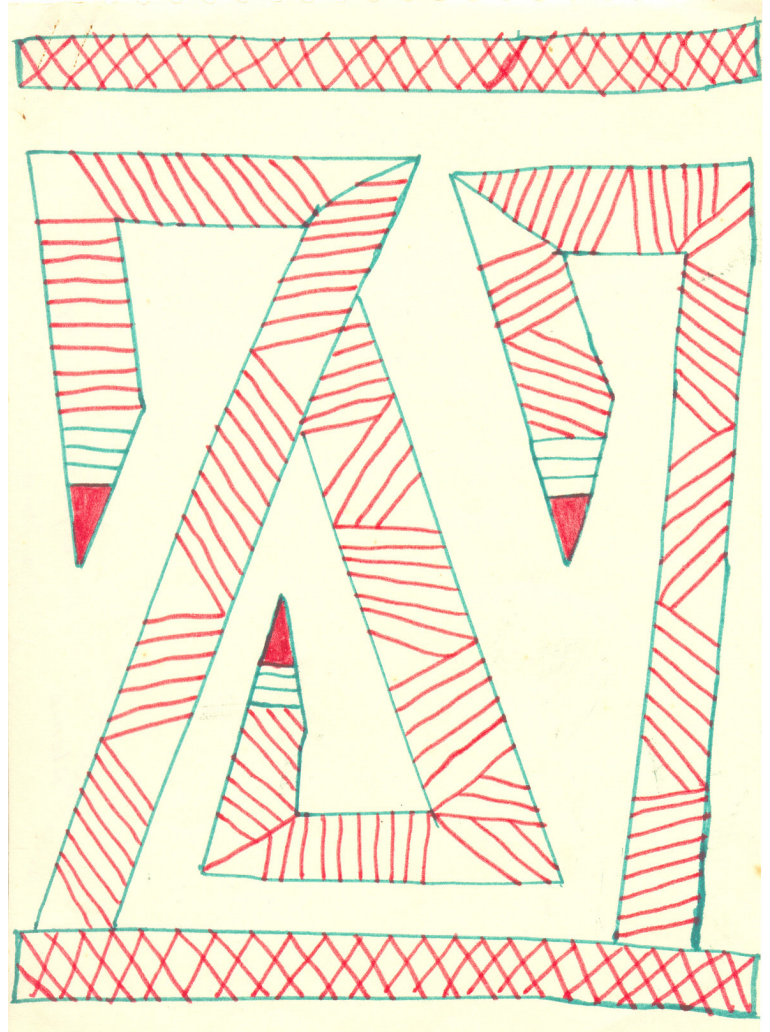

Figura 1: Registro sobre papel de grafismo de pintura corporal. Oficina de Saberes Wayana e Aparai, 2005.

tros termos, essa "estranheza" se deve ao fato de as produções indígenas serem concebidas e executadas em contextos que não compartilham das premissas ocidentais acerca da definição de "arte" e de sua finalidade, que estaria em si mesma, como afirmam muitos pensadores que trataram dessa matéria.

Sabemos que a arte é na realidade muito mais conceito do que fenômeno, não sendo, assim, homogeneamente definida pelas diferentes culturas indígenas, até porque partilha, com outros componentes culturais, de um modelo de experiência coletiva, de grande complexidade conceitual. Nessas sociedades, os enunciados estéticos vêm sancionar determinada visão de mundo que, em contextos variados, participa da definição das pessoas, assim como de suas relações e produções.

As diversificadas manifestações artísticas dos índios são sempre referidas, na mídia e também nos compêndios escolares, no singular, ou seja, "arte indígena". Entretanto, ao expressarem preocupações específicas, permitem a cada povo indígena desenvolver um estilo próprio, e, assim, aquela qualificação é equivocada enquanto meio de identificação, posto que não existe uma arte comum e geral dos índios. A referência requer sempre a pluralidade, a saber, "artes indígenas" para a correta identificação dessas artes, 


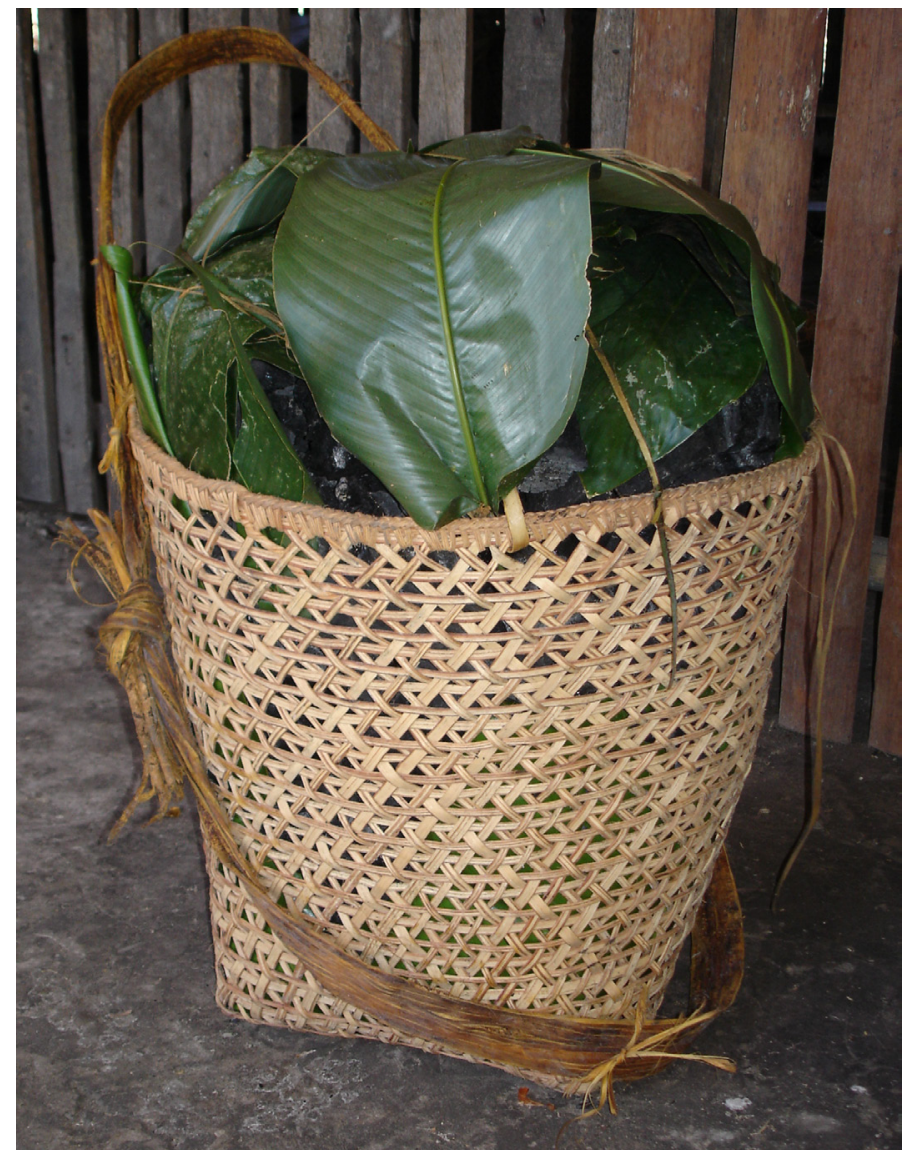

Figura 2: Cesto cargueiro dos Baré. Feito de cipó ambé, envira e com trançado "olho de piaba". Foto: Lucia van Velthem, 2008.

pois expressam tantas formas quantos são os povos que as produzem. Um ar familiar, facilmente perceptível através das matérias-primas empregadas, do aspecto formal de certos artefatos perpassa, entretanto, as artes indígenas, tornando-as distintas das produções de outras sociedades (RIBEIRO, 1987, p. 332).

Paralelamente, os artefatos indígenas são invariavelmente apreciados pelo senso comum enquanto "artesanato", termo institucionalizado pelos que os negociam em lojas de suvenir ou de artigos para decoração. Essa classificação aponta para a ideia de que as artes indígenas seriam anônimas e, assim, desprovidas de autoria individual. Ademais, segundo o pressuposto mais frequente, o artesanato estaria ligado à tradição, a um modo de vida pretérito, aspectos permanentemente associados às culturas indígenas (BARBOSA, 1995). A outra face dessa moeda é constituída pela aura de exotismo atribuída às produções materiais e imateriais indígenas, e aos próprios índios, porquanto esse rótulo constitui uma forma de neutralizá-los e aliená-los em um passado absoluto e preferencialmente remoto (VIVEIROS DE CASTRO in DAUBERT, 2005). (Figura 2) 
$\mathrm{Na}$ avaliação das artes indígenas, o olhar ocidental privilegia as categorias de maior impacto visual, como a plumária ou os objetos rituais, e não considera as demais produções. No entanto, o fazer artístico indígena não recai exclusivamente sobre os ornatos de penas e as máscaras; objetos de uso cotidiano podem apresentar elaboração formal e estética que transcende seu desempenho funcional (RIBEIRO, 1987). (Figura 2) Nas sociedades indígenas os esforços criativos alcançam muitos domínios, pois o campo abrangido pela "arte" é amplo e se expressa de diferentes formas, das mais efêmeras pinturas corporais às duradouras edificações, incluindo artefatos de uso cotidiano e ritual, manifestações performáticas e musicais. Os artefatos e os grafismos, em particular, materializam redes de interação complexas, condensando laços, ações, emoções, significados e sentidos (LAGROU, 2005:70).

Outro pressuposto considera que as artes indígenas se materializam quase exclusivamente pelas formas transportáveis e perecíveis, os artefatos. Os objetos indígenas resultam da execução de técnicas variadas, classificadas como cerâmica, entalhe, cestaria, plumária e tecelagem; apreciados, nas grandes cidades, em museus antropológicos ou em lojas de artigos turísticos. Do passado nos chegam tradições artísticas indígenas que se caracterizam pela extrema permanência, como os registros rupestres, pintados ou gravados nos abrigos ou afloramentos rochosos, encontráveis em praticamente todo o território nacional (PESSIS, 2004).

Apesar da grande diversidade de manifestações, as artes indígenas não são criadas para ser contempladas. Revestem-se antes de particularidades expressivas e constituem, na maior parte das vezes, meio para a transmissão de concepções de fundo social ou cosmológico. Possuem, dessa forma, funções representativas e utilitárias, além de outros objetivos e eficácias. A experiência estética constitui, para os índios, elemento fundamental na transmissão de conhecimentos e de valores sociais, por meio dos quais pode ser definida sua especificidade, ou seja, a natureza ou a essência de sua própria humanidade. Deve ter, portanto, apreciação que englobe igualmente outras expressões culturais. Nesse sentido, a valorização estética de um artefato indígena pode não estar contida no próprio objeto, mas se afirma ao exprimir uma relação, pois estaria condensada na própria utilização do artefato ou em sua permuta.

A qualidade estética também pode ser encontrada na adequação dos elementos constitutivos de um cesto ou de uma máscara, sendo imprescindível o uso de matériasprimas específicas. Ademais, em um artefato indígena, forma e função estão sempre intimamente relacionadas e a sua incorporação social e consequente percepção visual só se concretizam quando ele está terminado e, portanto, pode ser utilizado. A experiência artística indígena inclui um fazer e usufruto diário, que se revela até em coisas que julgaríamos secundárias, como o valor atribuído à alva coloração dos objetos recém-concluídos, em oposição aos utilizados que, por esse motivo, se tornaram encardidos.

As produções artísticas expressam, na vida indígena, os conhecimentos acerca das matérias-primas empregadas, das técnicas de confecção, do simbolismo agregado. Esses saberes se exercem em muitos campos da produção e da utilização e refletem 


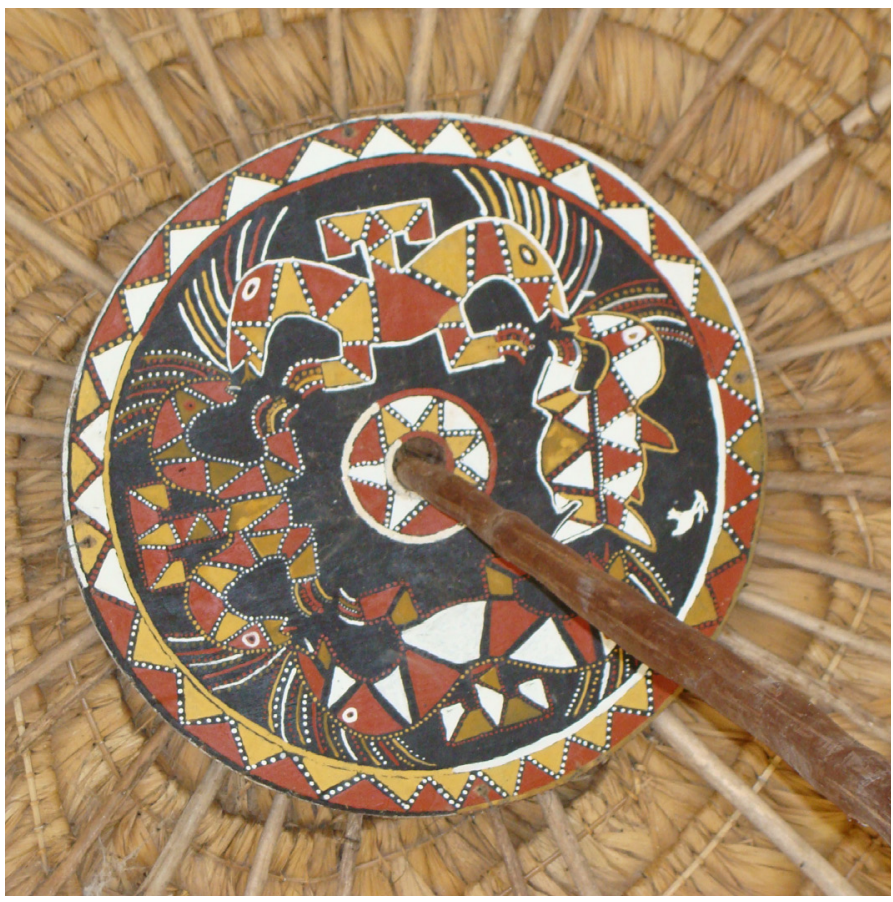

Figura 3: Roda de teto de casa cerimonial dos Wayana e Aparai com representações de serpentes sobrenaturais. Foto: Iori Linke, 2009.

um longo aprendizado. Assim, observa-se que a maestria técnica e artística está invariavelmente acompanhada de profundo conhecimento das narrativas míticas e das práticas rituais, constituindo domínios estreitamente associados (GUSS, 2003). Para muitos povos da Amazônia, a origem mítica da arte gráfica é atestada, evidenciando sua vinculação com seres específicos que remetem às cosmologias, teorias nativas globalizantes.

Os métodos das artes indígenas e os sentimentos que as animam são, portanto, inseparáveis, não sendo possível compreendê-los como encadeamento de formas, mas antes como um mecanismo cognitivo que serve, sobretudo, para ordenar e definir o universo social e o não social, o humano e o não humano. Constituem, assim, meio para o armazenamento e a transmissão de informações que se caracteriza por ser compartilhado, pois os elementos estéticos possuem uma lógica que é compreendida pelo artista e pelo grupo ao qual pertence, acarretando o desenvolvimento de um "estilo próprio", peculiar a cada povo indígena. Os estudos realizados até o presente definiram dois enfoques principais que fundamentam os diferentes estilos (VIDAL E SILVA, 1992). Assim, diversas culturas privilegiam conceitos e representações mais especificamente ligados às relações estabelecidas entre indivíduos e grupos em sociedade, veiculando mensagens sobre a posição social e individual de seus criadores e usuários. Outras sociedades estão mais diretamente relacionadas aos conceitos cosmológicos e refletem concepções acerca dos componentes do universo, sobretudo dos que estão alijados da sociedade, os mortos, os inimigos, os animais, os sobrenaturais. (Figura 3) Sobressaem as figuras das gran- 
Figura 4: Menino tecendo o grafismo

"olho do gavião real". Foto: Lucia van Velthem, 2007.

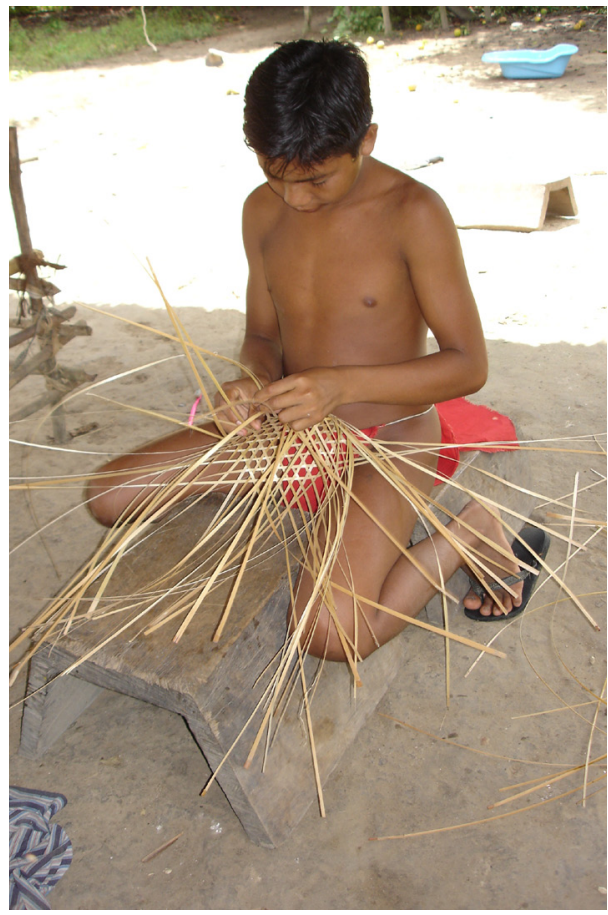

des serpentes amazônicas, jibóia e sucuriju, enquanto "mestres" ou "donos" originais dos sistemas gráficos de diferentes povos indígenas, destacando-se os de língua carib.

As artes indígenas delineiam uma visão de mundo específica, na qual a forma humana não constitui garantia de humanidade (VILAÇA, 2005). Assim sendo, uma máscara ou grafismo que possua características antropomorfas não representa, necessariamente, um ser humano específico, mas remete a concepções subjacentes acerca da humanidade, permitindo às artes indígenas apresentar-se como culturalmente densas. De modo paralelo evidencia-se o fato de que algumas formas gráficas parecem abstratas a um olhar desatento, mas, na realidade, configuram representações iconográficas. Isso significa que entre o modelo e a representação existem elementos que podem ser reconhecidos (PIERCE, 1977) pelo produtor e seus pares comunitários (Figura 4). Isso ocorre porque em algumas sociedades indígenas o papel dos grafismos é o de transmitir simultaneamente a percepção sintética de múltiplas realidades, aspecto que é expresso através do formal e do conceitual.

\section{CORPOS E COSMOS}

A questão da corporalidade é central na vida indígena e está vinculada a um sistema de relações entre corpos, bem como ao pensamento de que a humanidade de um corpo não é inata, mas deve ser construída culturalmente, de modo contínuo (VILAÇA, 2005). São assim desenvolvidas práticas que objetivam facilitar a transformação de um 


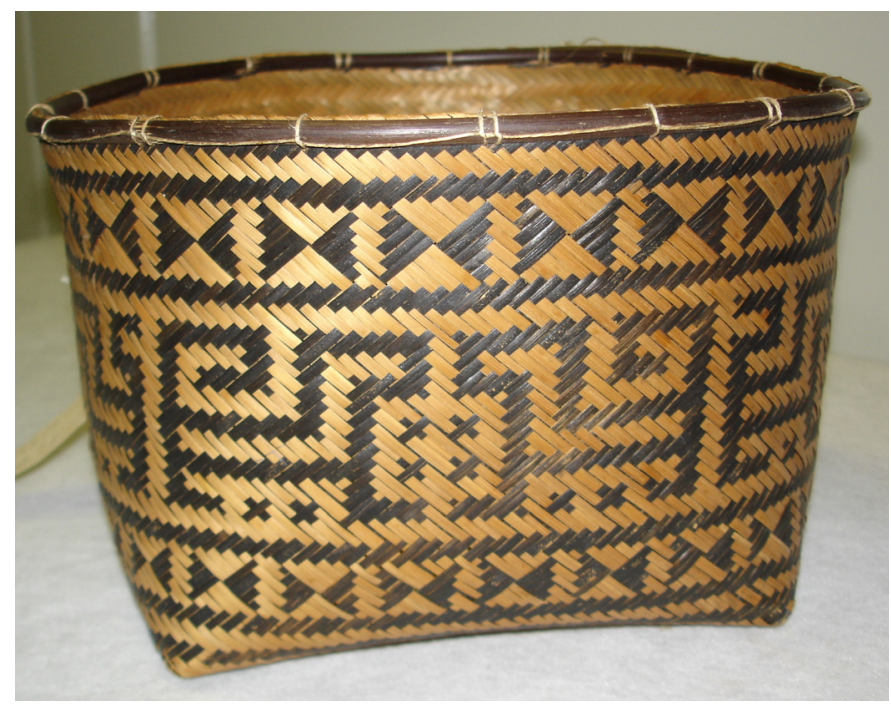

Figura 5: Cesto

wayana com

grafismos

de múltipla

representação,

animal e

sobrenatural.

Foto: Lucia van

Velthem, 2007.

corpo para dotá-lo das qualidades sociais requeridas, assim como para modificar sua natureza e seu aspecto. Através de técnicas variadas e complexas são efetivadas amplas mudanças corporais, algumas das quais relacionadas a uma elaboração estética, geralmente reunidas sob a expressão "decoração" corporal. A elaboração do corpo é produzida tanto por pinturas de base vegetal - o vermelho vem do urucu, o negro, do jenipapo - como por tatuagens, escarificações, adornos plumários e de outros materiais, e também pelo corte de cabelo. Constituindo parte essencial do processo de transformação da pessoa, essas técnicas comunicam diferentes intenções e são específicas de cada povo indígena.

A elaboração plástica, dotada de sentido decorativo não se restringe aos humanos, mas também se aplica aos artefatos, como cestos, remos, recipientes cerâmicos, bancos, cuias, cabaças, em que se percebem variações formais, reveladoras das técnicas decorativas empregadas, como a pintura, as incisões, as amarrações. Humanos e objetos são igualmente decorados porque compartilham uma série de faculdades, entre as quais a antropomorfia, uma vez que para muitos povos indígenas os artefatos são compreendidos enquanto seres corporificados ou antes representam corpos ou partes deles. Os corpos dos objetos não remetem necessariamente aos humanos, pois os modelos podem ser animais, seres arquetípicos ou sobrenaturais, que adquirem assim visibilidade e capacidade de ação em determinados momentos da vida social.

A decoração, tomada em sentido amplo, constitui uma intervenção que é tanto técnica como simbólica e objetiva o embelezamento e a impressão de determinada marca social em pessoas e coisas. Essa intervenção atinge a própria essência dos elementos que a sofrem, seja o corpo humano ou a estrutura de um artefato, que de outra forma estaria incompleto e despersonalizado culturalmente. Em certo sentido, a decoração os 
criaria, confirmando sua função social, como apontado por Lévi-Strauss a respeito dos índios de Mato Grosso do Sul. Os propósitos específicos da decoração são variados, podendo direcionar-se para a identificação étnica e da condição humana ou então para a apropriação de qualidades desejáveis, um meio de interação com o mundo sobrenatural ou como uma possibilidade de expansão visual para que sejam percebidos, através dos grafismos, aspectos ocultos da visão ordinária. (Figura 5)

Os Wayana, que vivem no norte do Estado do Pará, compreendem que o cosmo é povoado por seres e elementos cujos corpos são providos de revestimento reconhecido como "pele", aspecto que é compartilhado por humanos e não humanos, animais, vegetais, sobrenaturais, demiurgos. A ênfase conferida a esse elemento deriva do fato de que sua visualização representa importante meio de identificação, operante entre os membros de um mesmo domínio e entre os diferentes domínios. Esse aspecto é efetivado mediante elementos gráficos e cromáticos que são compreendidos como "pintura corporal".

Essa percepção constitui para os Wayana uma possibilidade de diferenciação através da ornamentação corporal, uma vez que todos os componentes cosmológicos a possuem. A mais inclusiva é aquela que permite distinguir diferentes domínios, pois a cada um corresponde uma forma decorativa específica: unicolor, pontilhado e listrado. Essas intervenções são iconográficas porque descrevem com precisão a estética corporal de um ser paradigmático, identificando-o e, paralelamente, ao domínio a ele associado. O unicolor é uma superfície uniforme, recoberta de uma tintura culturalmente elaborada e, portanto, constitui a decoração corporal dos humanos. Outra forma decorativa, o pontilhado, define-se enquanto uma superfície recoberta por manchas circulares e reproduz iconicamente a pelagem da onça-pintada, um dos mais significativos animais. Metonimicamente faz referência aos demais animais e ao espaço em que evoluem. A decoração listrada consiste em uma superfície com listras horizontais e verticais de cores contrastantes e representam iconograficamente o arco-íris. Esse fenômeno constitui a manifestação física de uma serpente/enguia sobrenatural e o identifica, assim como a outros sobrenaturais que comungam não somente da mesma potencialidade, e ainda a própria sobrenatureza que se revela através de seus representantes.

A decoração uniforme, pontilhada ou listrada pode ser, através de varias técnicas, transposta para um objeto, e sua principal função consiste no preenchimento dos campos vazios, formados pelo tracejado dos motivos. Como é possível que algum artefato apresente todas essas unidades, evidencia-se um sentido de recapitulação do todo, uma vontade de síntese que é a essência da arte wayana, determinando de alguma forma seu estilo. Ademais, a decoração corporal dos componentes cosmológicos possui dois níveis de apreensão, derivados de diferentes técnicas. No mais evidente, ela é aplicada, como ocorre na pintura corporal dos humanos ou na de objetos, tais como os vasilhames cerâmicos. Em outra modalidade, a decoração e o suporte são indissolúveis, como se apresenta nos animais, vegetais, seres sobrenaturais e também nos artefatos tecidos e trançados. Uma ornamentação intrínseca, ou seja, um repertório decorativo que, em sua origem, constitui o próprio suporte, define esses seres como "permanentemente de- 


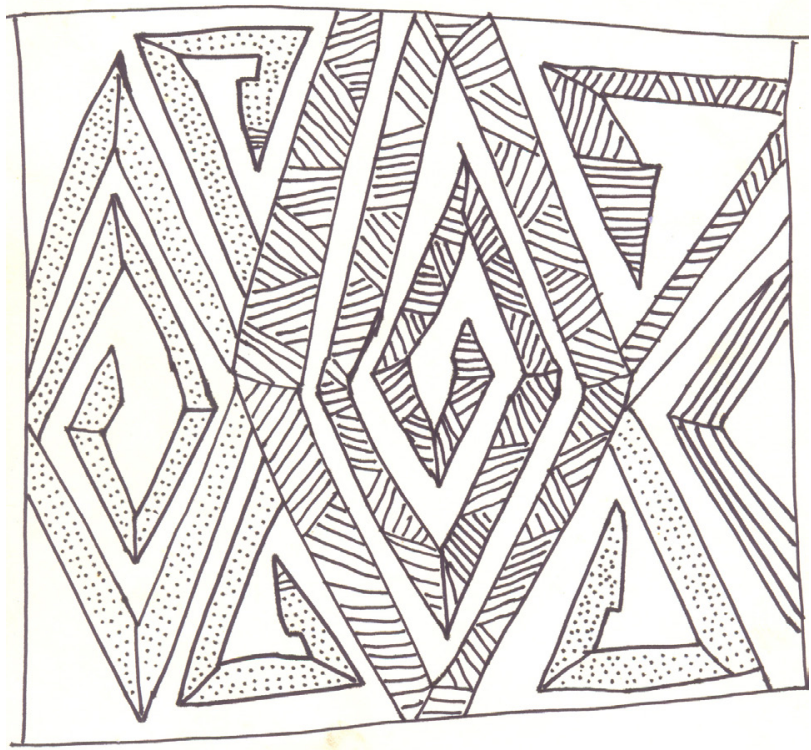

Figura 6: Grafismo wayana de pintura corporal de jenipapo. Desenho sobre papel: Dola, 1984.

corados". A decoração corporal dos humanos é aplicada e, portanto, cambiável, pois se adapta às mudanças básicas de sua vida. No cotidiano é uniforme e vermelha do urucu, no ritual é gráfica e preta do sumo do jenipapo. (Figura 6) Essa alternância identifica os humanos enquanto seres "temporariamente pintados". O corpo/pele humana representa o mais importante meio de construção de uma identidade social e individual que é justamente reforçada pela capacidade que os humanos têm de cambiar sua estética corporal e, dessa forma, transformar-se, o que não é facultado aos demais componentes cosmológicos.

Para os Wayana, assim como para muitos povos indígenas, a permanência das formas de expressão artística está em constante desequilíbrio. $O$ incremento das relações com a sociedade envolvente, as frequentes visitas aos centros urbanos, a ação missionária que visa desestruturar prioritariamente a ornamentação corporal, a introdução do vestuário ea presença da escola nas aldeias constituem alguns dos fatores que acarretam a perda das condições indispensáveis para sua significação, usufruto e transmissão. A manutenção da estética corporal e das demais artes indígenas depende grandemente do equilíbrio social e ambiental de cada povo, o qual é prioritário na preservação e valorização dos sentidos e das dinâmicas próprias de comunicação e experimentação desses saberes e práticas.

\section{REFERÊNCIAS BIBLIOGRÁFICAS}

BARBOSA, W. La artesanía indígena y el tráfico simbólico. Artesanías de América. Revista del Cidap: 46-47, 1995: 131-152. 
DAUBERT, M. L'exotisme est une forme de narcissisme? Entretien avec l'anthropologue Eduardo Viveiros de Castro. Les indiens du Brésil. 2005. Telerama Hors Serie.

GALLOIS, D. (org.). Patrimônio cultural imaterial e povos indígenas: exemplos no Amapá e Norte do Pará. São Paulo: lepe, 2006.

GUSS, D. To weave and sing. Art, symbol, and narrative in the South American rain forest. California: University of California Press, 1990.

LAGROU, E. L'art des indiens du Brésil : alterité, "authenticité" et pouvoir actif. In: GRUPIONI, L.D. (org.). Brésil Indien: les arts des Amérindiens du Brésil. Paris: Éditions de la Réunion des Musèes, 2005: 68- 87.

NAHOUN-GRAPPE, V. Introduction. Le jugement de qualité. In: NAHOUN-GRAPPE, V. e VINCENT, O. (orgs.) Le gout des belles choses: etnhologie de la relation esthétique. Paris: Éditions de la Maison des Sciences de l'Homme, 2004: 1-8.

PESSIS, AM. A transmissão do saber na arte rupestre do Brasil. In: DANTAS, M. (ed.). Antes. Histórias da Pré-História. Catálogo. Centro Cultural Banco do Brasil, 2004: 142-163.

PIERCE, C. Semiótica. São Paulo: Ed. Perspectiva. 1977.

RIBEIRO, D. Suma Etnológica Brasileira III: arte índia. Petrópolis: Vozes, 1987: 29-64.

VELTHEM, L.H. van. Das cobras e lagartas: a iconografia Wayana. In: Vidal L. (ed.). Grafismo indígena: estudos de antropologia estética. São Paulo: Studio Nobel/Fapesp/ Edusp, 1992: 53-66.

. A pele de Tuluperê: uma etnografia dos trançados Wayana. Belém: Museu Paraense Emílio Goeldi. 1998.

. Faces da cerâmica indígena. In: SANJAD, N. (ed.). Artes da Terra. Resgate da cultura material e iconográfica do Pará. Belém: Edição Sebrae, 1999: 54-63.

. Os primeiros tempos e os tempos atuais: artes e estéticas indígenas. In: AGUILAR, N. (ed.). Artes indígenas: Mostra do Redescobrimento. Catálogo. São Paulo. 2000: 58-91.

. O belo é a fera: a estética da produção e da predação entre os Wayana. Lisboa: MNE/Assirio e Alvim. 2003.

Les mains, les yeux, le movement: les tressages des Indiens au Brésil. In : Brésil Indien: les arts des amérindiens du Brésil. Paris: Éditions de la Réunion des Musèes, 2005: 214-241.

. Artes Indígenas. Herança viva de outros tempos. In: FURTADO, R. (org.). Scientific American Brasil. São Paulo: Duetto Editorial. Coleção Amazônia. Origens, 2008: 56-63.

VIDAL, L. e SILVA, A. Antropologia estética: enfoques teóricos e contribuições metodológicas. In: Grafismo Indígena. Estudos de antropologia estética. São Paulo: Studio Nobel/ Fapesp/Edusp, 1992: 279-293.

VILAÇA, A. Chronically unstable bodies: reflections on Amazonian corporalities. Journal of Royal Antropological Institute (N.S.), 11, 2005: 445-464.

Lucia Hussak van Velthem é museóloga, doutora em Antropologia Social pela USP, pesquisadora titular do $\mathrm{MCT}$, atualmente na Subsecretaria de Coordenação das Unidades de Pesquisa (SCUP) , em Brasília. Tem desenvolvido pesquisas sobre arte, estética e cosmologia entre os Wayana e Aparai (PA) e sobre cultura material entre os Baré e Tukano (AM) e entre agricultores familiares $(A C)$. 
